\title{
Estimation of erosion-accumulative processes at the Inia River's mouth near high-rise construction zones.
}

\author{
Natalya Sineeva ${ }^{1, *}$ \\ ${ }^{1}$ Novosibirsk State University of Architecture and Civil Engineering, 630099 Str. Leningradskaya \\ 113, Novosibirsk, Russia
}

\begin{abstract}
Our study relevance is due to the increasing man-made impact on water bodies and associated land resources within the urban areas, as a consequence, by a change in the morphology and dynamics of Rivers' canals. This leads to the need to predict the development of erosionaccumulation processes, especially within the built-up urban areas. Purpose of the study is to develop programs on the assessment of erosionaccumulation processes at a water body, a mouth area of the Inia River, in the of perspective high-rise construction zone of a residential microdistrict, the place, where floodplain-channel complex is intensively expected to develop. Results of the study: Within the velocities of the water flow comparing, full-scale measured conditions, and calculated from the model, a slight discrepancy was recorded. This allows us to say that the numerical model reliably describes the physical processes developing in the River. The carried out calculations to assess the direction and intensity of the channel re-formations, made us possible to conclude, there was an insignificant predominance of erosion processes over the accumulative ones on the undeveloped part of the Inia River (the processes activity is noticeable only in certain areas (by the coasts and the island)). Importance of the study: The study on the erosion-accumulation processes evaluation can be used in design decisions for the future high-rise construction of this territory, which will increase their economic efficiency.
\end{abstract}

\section{Introduction}

Small water objects of Novosibirsk lost their former importance. Over the past 40-50 years Novosibirsk water objects no longer are used take water for household needs, drinking, and their fishery value is practically lost. The Inia River is not an exception in this sense, since it flows through a territory subjected to anthropogenic influences. The indirect source of influence on the water flow and sediment in the estuary area of the Inia River, located within Novosibirsk, is the Novosibirsk hydroelectric complex, the natural course of water levels in the section of the Inia River is distorted by influence of the Obi River backwater. The increased source, in comparison with the "natural", sediment inputs in the Inia River within the city of Novosibirsk are HPS-5, Borok quarry, Sibtransmash plant. All of them contribute finely-dispersed material in the River, which has a high adsorption capacity, immobilizes various elements, organic compounds, oil products, and in its turn there is the

\footnotetext{
${ }^{*}$ Corresponding author: ief@sibstrin.ru
} 
source of secondary River pollution, for example, under condition of the project's implementation for the River canal and coastal areas improving. The project of the small city River improvement may include clearing the channel, relief geo-plasticity, bank protection structures, retaining hydraulic structures, etc. In any case, this contributes to a change in the geometry of the River channel, for example, it's narrowing and, as a consequence, channel processes activation, such as deep or lateral erosion.

In this regard, it is necessary to improve hydrological and ecological monitoring, which includes not only a system of observations, but also an assessment, and a forecast of changes in the water bodies state, erosion-accumulation processes, the direction and intensity of channel reorganization. Carrying out of such works involves modern computer systems adaptation.

The present work was carried out on a grant of the Novosibirsk City Mayoralty. The main goal of the work is the numerical model adaptation for the assessment of the direction and intensity of channel deformations for the River mouth in the zone of perspective highrise build-up of a residential microdistrict, developed by the Institute of Water and Environmental Problems of the SB RAS, by Dr. phis.-mat. sciences, V.A. Shlychkov. As an initial data, an explanatory note to the project for the planning of the residential, publicbusiness and recreational area (the Inya River mouth) was send to the city mayor's office

In order to achieve this goal, three main tasks are formulated, the first two of which are aimed at obtaining the initial data for the mathematical model adaptation:

1. Analytical study of bottom sediments of Inya mouth region, which allows obtaining data on their composition and properties, including the study of granulometric, mineral compositions and organic constituents.

The density and moisture capacity of bottom sediments, which determine the ability of soils to water exchange, depend on the granulometric composition. Water exchange affects the rate of chemical reactions, physico-chemical exchange processes, and a number of biological processes in soils. Many of their physical, physical - chemical and chemical properties were associated with the mineral constituent of the bottom sediments. Obtaining data on the organic matter amount is important, since organic matter is involved in the formation of compounds complexes with finely dispersed silty or colloid fractions of inorganic components that are suspended or in bottom sediments (metals, clay particles, etc.). Organic acids (acetic, oily, etc.), carbohydrates, proteins, fats, amino acids, humic substances, esters, enzymes were found in natural waters.

The whole complex of organic substances is continuously transformed, some substances disintegrate, and others are formed. Organic carbon is a reliable indicator of the total content of organic matter in natural waters. Humic and fulvic acids make up a significant part of the surface waters' organic matter.

Thus, bottom sediments are considered as a multiphase heterogeneous system of an open type, exchanging substances and energy with other media.

2. Hydrometric survey of a water body with the channel reception survey of the Inya River mouth's speed structure, turbidity of the water, water flow and slope of the water surface.

3. Performing process on a numerical experiment to assess the direction and intensity of channel re-formations, which includes the following main stages: analysis of natural-natural factors and hydraulic features of the River section; selection of source materials containing full-scale hydrometric and morphometric information; the formation of a digital terrain model in the nodes of a regular grid with a given spatial resolution; a curvilinear finite-difference grid generating, taking into account the geometry of the solution domain and the requirements for spatial detail, which provides the required accuracy of calculation; the formation of initial fields and boundary conditions for the numerical model; study the of the model sensitivity and calibration of parameters based on actual information; the carrying out of working calculations, analysis and interpretation of the results. 


\section{Materials and Methods}

The numerical experiment is a leading method to evaluate the direction and intensity of channel deformations based on two-dimensional numerical models developed by the Institute of Water and Environmental Problems of the SB RAS, by Dr. phis.-mat. sciences, V.A. Shlychkov. With a purpose to obtain the initial data for the purpose of mathematical models adaptation, bottom sediments were studied at different points of the River section to determine the granulometric, mineral composition and organic component by laboratory methods, according to N.A. Kachinsky works; quantitative X-ray phase analysis; I.V. Tyurin (in the modification of V.V. Ponomareva and T.A. Plotnikova). The hydrometric survey of the water body was carried out in accordance with the adopted recommendations.

1. Determination of the granulometric composition.

Within the present framework, the bottom sediments' granulometric composition of River silts (as well as the mineral composition and content of organic substances) was studied by selecting a number of samples in the River canal, followed by their laboratory treatment. The study of the bottom sediments' granulometric composition was carried out in the soil biogeochemistry laboratory of the Institute of Soil Science and Agrochemistry of the SB RAS using N.A. Kachinsky method, based on the relationship between particle sedimentation rate in an aqueous medium and their diameter (O.B Kuznetsova. et al, 2014).

2. Determination of mineral composition.

On the basis of the Geochemistry Laboratory of Rare Elements and Ecogeochemistry and the X-ray structural analysis laboratory of the Joint Institute of Geology, Geophysics and Mineralogy of the SB RAS, an analysis of the bottom sediments' mineral composition of the object was made. This study was carried out using quantitative X-ray phase analysis with a help of the DRON-3 diffractometer (Fetisov GV, 2007), which made it possible to determine the intensity dependence of the phase diffraction peaks being determined from its content in the sample.

3. Determination of organic constituents.

The study of organic constituents was carried out at the Institute of Soil Science and Agrochemistry of the SB RAS using the laboratory method of chemical analysis according to I.V. Tyurin scheme (modified by V.V. Ponomareva and T.A .Plotnikova) (O.B. Kuznetsova et al, 2014) content of organic carbon; brown humic acids carbon; fulvic acids carbon was defined.

4. Hydrometric survey.

Hydrometric surveys were carried out at the mouth of the Inia River near the motor bridge (Fig 2). In order to obtain channel survey, investigations were carried out using the Garmin GPS 178c measuring complex, which allows depth measurements with an accuracy of up to $0.1 \mathrm{~m}$ and determine positions in geographic coordinates, depending on the number of satellites with an accuracy of $1 \mathrm{~m}$ (Lyakhin Yu.S. \& Perepelitsa D.I., 2009). Also, the positions of the left and right coast water cuts were recorded. Measurements of flow velocities by a hydro-metric turntable of the GR-21M mark were made in the measuring section at the site in question. Determination of water consumption and the discharge of suspended sediments was carried out according to recommendations of (Bespalova L.A. \& Berdnikov S.V., 2016). The water flow rate is calculated by analytical $\left(Q=\int_{F} V d f\right)$ and grapho-analytical $\left(Q=\int_{B} q d b\right)$ by the ways, where $F-$ flow area, $\mathrm{m}^{2} ; V-$ speed, $\mathrm{m} / \mathrm{s} ; q-$ specific consumption, $\mathrm{m}^{2} / \mathrm{s} ; B$ - width of the River, $\mathrm{m}$. The rate of suspended silts was determined analytically. The water level fluctuations were recorded on the water gauge rail. To determine the turbidity of the water flow (mass concentration of suspended sediments), 
water samples were taken by the bottles of GR-16M with subsequent processing of the selected samples.

\section{Equations and mathematics}

Mathematical modeling to assess the direction and intensity of channel deformations was carried out on the basis of two-dimensional numerical models, developed by developed by the Institute of Water and Environmental Problems of the SB RAS, by Dr. phis.-mat. sciences, V.A. Shlychkov. Numerical experiment is based on two models having the following blocks in this research paper:

1. двумерная, вертикально осредненная модель плановых течений в водоемах суши (гидродинамическая составляющая);

2. модель транспорта наносов и деформации русла (деформационная составляющая).

1. two-dimensional, vertically averaged model of planned currents in the land's water bodies (hydrodynamic component);

2. model of the silts transport and deformation of the River canal (deformation component).

Из всего многообразия формул для расхода наносов в качестве базы использовалась хорошо апробированная и широко применяемая в расчетах зависимость Бэгнольда, не предусматривающая деление наносов на взвешенные и донные. Формула Бэгнольда базируется на анализе мощности, расходуемой потоком на перемещение твердых частиц (Боровков В.С., 1989). Соотношение для насыщающих значений $\mathcal{C}_{*}$ концентрации выглядит как

Of all the formulas' varieties for sediment discharge, a well-tested and well-known Bagnold correlation was used as a base, which did not involve the division of silts into suspended and bottom sediments. Bagnold's formula is based on the analysis of the power consumed by the solid particles flow (Borovkov V.S., 1989). The ratio for saturating concentration $\mathcal{C}_{*}$ values looks like

$$
c_{*}=\sigma \frac{u_{*}^{2}}{g h}\left(\frac{e}{\operatorname{tg} \varphi}+0.01 \frac{|\mathbf{u}|}{w_{g}}\right)
$$

where $\rho, \rho_{c}-$ density of water and solid slurry material, $\sigma=\rho_{c} / \rho$ - relative density of alluvium, $u_{*}$ - friction speed, $e$ - coefficient that takes into account the energy losses for sediment transport, $\varphi \approx 32^{\circ}$ - angle of internal friction of sediments in water, $w_{g}$ hydraulic size. Variable-free expression (1) sets the total critical concentration of suspended and attracted sediment; the first term in parenthesis (1) determines the velocity of sediment transported, the second is suspended. The total sediment consumption by Bagnold is written as

$$
\mathbf{q}_{b}=h \mathbf{u} c_{*}
$$

We now state the boundary conditions..In the input line, the total flow of the River is known $Q_{1}$. In the cross-section of the output line, the level of the free surface is recalculated into depths $h$.

The hydrodynamic problem statement closes the initial conditions on the velocity components $u=v=0$ and spatial distribution of depths $h$ in moment The required 
parameters of the flow were obtained by integrating the equations of Saint-Venant's planned currents in time before reaching the steady-state regime (Shlychkov V.A., 2008).

The main numerical experiments were carried out under steady-state flow conditions with a water flow rate $Q=34,01 \mathrm{~m}^{3} / \mathrm{s}$. One of the numerical model components for determining the rate of deformation is the digital model of the River channel relief, which was built on the basis of the field surveys' results. The problem was solved in two stages. First, a vector velocity field was calculated $u, v$ and the scalar field of the stream depths $h$, corresponding to a given flow rate $Q$. At the second stage, the trends of the basic deformation processes were determined on the basis of the previously calculated velocity field characteristics.

\section{Results}

1. The granulometric composition curve of the bottom sediments is shown in Fig. 1. Investigation of the granulometric composition showed that the bottom sediments of the Inia River mouth area. In accordance with the accepted classification (Kramarenko V.V., 2016) is represented by sand, dust and mud.

2. X-ray analysis of the bottom sediments' mineral constituent showed the presence a large part of rock minerals of massive crystalline magmatic origin (quartz and acid plagioclase (in the sum of $\approx 60-70 \%$ ). And also the presence of dense and loose sedimentary rocks: carbonates are represented by calcite; clay minerals are present in a subordinate amount: illite, chlorite, smectite; trace amounts (no more than $10 \%$ of the total) marked potassium feldspar and hematite

3. The results of the determination of the organics' fractional composition (humic acids, fulvic acids, insoluble residue of sediments) are expressed as a percentage of the total organic carbon content of more than $10 \%$. The value of the sediments' insoluble residue (53.4\% of the total organic carbon of the sample) characterized the fixing strength of substances with the clay fraction and the degree of the organic matter humification.

4. The total length of the channel survey was $500 \mathrm{~m}$ (Figure 2). Based on the research results and geodetic work, a plan of the channel section was constructed in the isobaths - in $0.25 \mathrm{~m}$ (Fig. 3) at a given working water surface level, and also the morphometric characteristics of the channel in the adopted section were determined: the area of the water section is $131.12 \mathrm{~m}^{2}$; the River width along the working level of the water surface is 108.4 $\mathrm{m}$; average depth is $1.2 \mathrm{~m}$; The maximum depth was $2.0 \mathrm{~m}$. The velocity of the water flow was measured on 12 high-speed verticals in a detailed way in a real gauging gate. The values $131,12 \mathrm{M}^{2}$; of the average velocities on the verticals are in the range $0.192 \ldots 0.346$ $\mathrm{m} / \mathrm{s}$. The flow rate of the water flow, calculated analytically, is $33.89 \mathrm{~m}^{3} / \mathrm{s}$, and graphoanalytical is $34.13 \mathrm{~m}^{3} / \mathrm{s}$. The calculated flow of suspended sediment is 2612,002 $\mathrm{g} / \mathrm{s}$. 


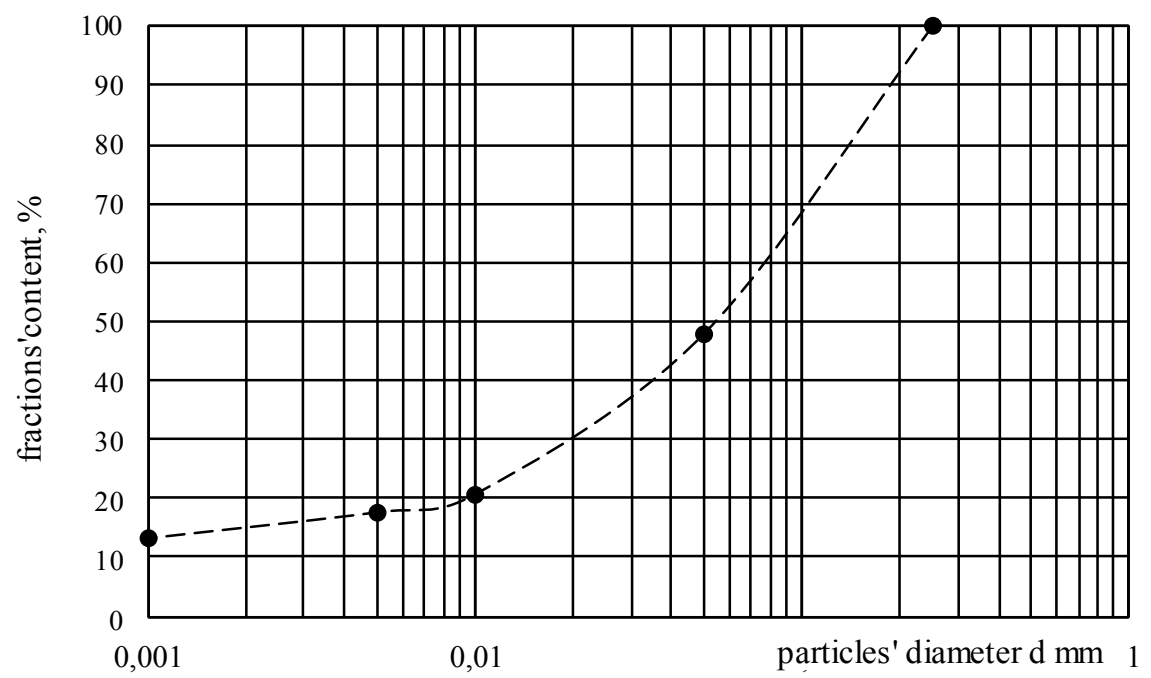

Fig 1. Curve granulometric composition of the bottom sediments in the Inia River's estuary region

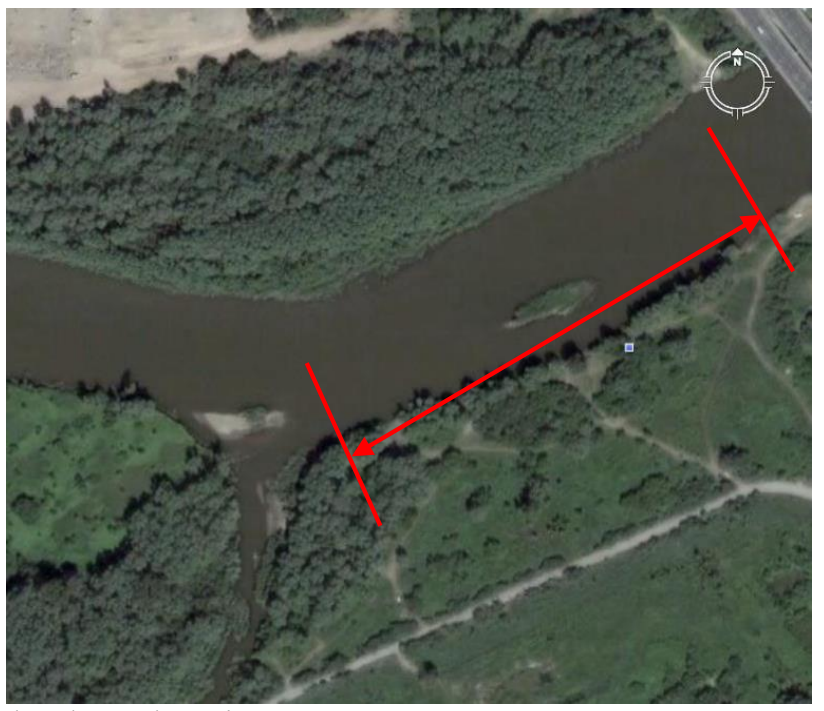

Fig 2. Space shot of the channel section 
Fig 3 Channel survey of the area.

5. Results of mathematical modeling.

The purpose of the calculations was to study the features of erosion and sediments' accumulation in the selected area of the Inia River in "domestic" (natural) conditions. Undoubtedly, its further urbanization strengthening will make significant changes in channel processes.

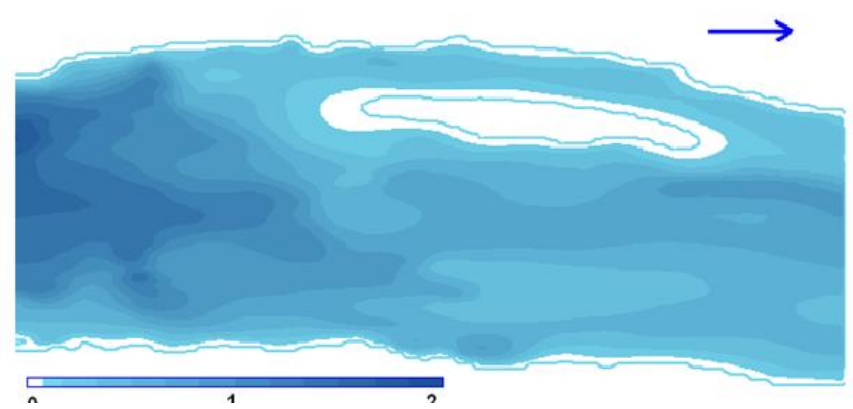

Fig 4 Depth field the Inia River' area. It shows the depth field of the River section, constructed using the planned numerical model used

As a result of calculations in the Inia River' area, the prevalence of erosive processes over accumulative ones was revealed; there is a tendency to erosion along the right bank along the River, where the highest erosion values (up to $1.4 \mathrm{sm} /$ day) are observed in the area 100-200 $\mathrm{m}$ from the origin, as well as in the middle of the left side and the most of the left (small) (Fig 5). The average erosion values in the area under consideration are 0.12 $\mathrm{sm} /$ day, accumulation is $0.09 \mathrm{sm} /$ day, a pronounced erosion process occurs only near the coast and the island. 


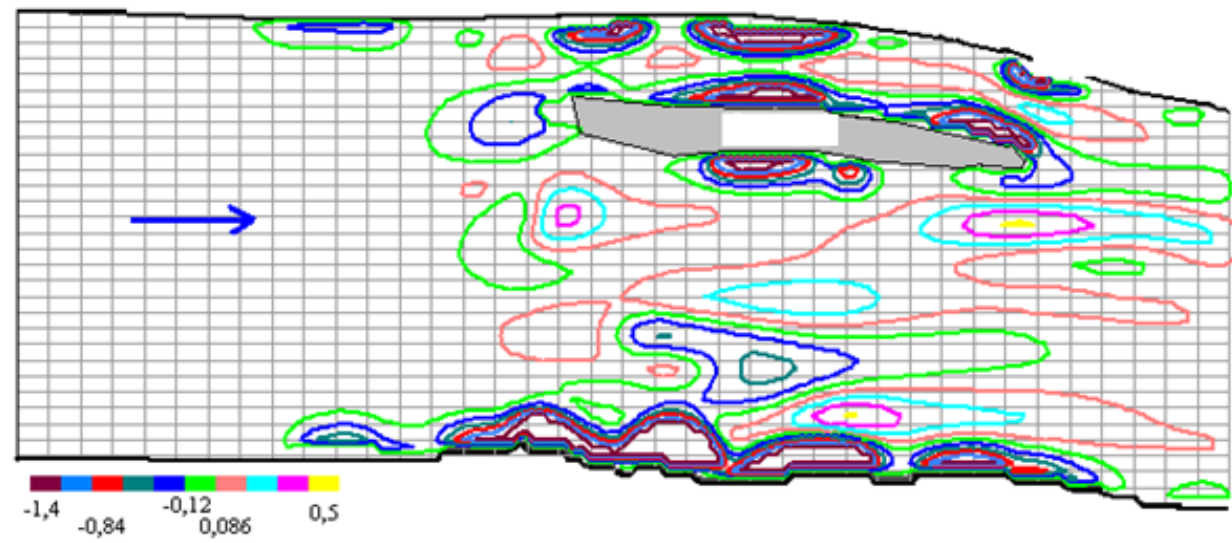

Fig 5. Tendencies of erosion and accumulation processes in the River section

The process of accumulation is clearly expressed on the right side of the island (yellow color in Fig 5), the strain rate is $0.5 \mathrm{sm} /$ day. The same intensity of deformations occurs in places of flow velocities decreasing, which causes the acceleration of sedimentation processes and the gradual accumulation of sediments. In the area, which is near the motor bridge and to the island in the area in question (0-100 $\mathrm{m}$ from the origin), the intensity of erosion-accumulation processes is an order of magnitude lower than in the narrowing of the water flow (about 100 meters further from the origin).

\section{Discussion}

1. The granulometric, mineral compositions and of the bottom sediments' organic constituents of the Inia estuary region were studied. The obtained data are presented in the form of a granulometric graph and a descriptive part and used in the adaptation of a numerical model.

2. In order to obtain the initial information on the main water flow hydraulic characteristics, a hydrometric survey was carried out for the mathematical calculations of channel deformations in the River region of its mouth area. It is no more than $500 \mathrm{~m}$ long in the zone of direct residential microdistrict's construction.

3. The performed calculations on the evaluation of the direction and intensity of the channel reorganizations made it possible to adapt the mathematical model in terms of orientation and intensity (Shlychkov V.A., 2008). Also, the results made it possible to conclude that there is an insignificant predominance of erosion processes over accumulative processes in the area in question (mainly, in some areas, near the coast and the island). In general, we can talk about the approximate state of the dynamic equilibrium, characteristic of natural conditions.

\section{Conclusion}

Strengthening the urbanization factors will contribute to pollution of the River channel, regime violation of the levels and flow rates, channel regime, which can lead to the development of irreversible channel changes that can not be eliminated without a directed engineering impact. The task of regulating channel processes is to provide the necessary hydraulic, operational, ecological indicators of the River channel as a whole. In this regard, 
the hydrological-ecological monitoring is rather important, its main tasks of are: regular observations of the natural characteristics' current state; identification of factors and patterns of technogenic and natural changes in ecosystems in time and space; these changes assessment; modeling and forecasting of changes in water systems under anthropogenic impact; development of recommendations for nature management processes.

\section{References}

1. O.B. Kuznetsova, O.I. Shirikova, Z.V. Kireeva, Korobeinikova, Chemical methods of studying the state of the environment (Vologda, 2014)

2. G.V. Fetisov, Synchrotron radiation. Methods for studying the structure of substance: (OOO Publishing company "Physics and Mathematics ", Moscow, 2007)

3. Yu.S. Lyakhin, D.I. Perepelitsa, Experience of using combined echo sounders with GPS and GIS-technologies for constructing cart diagrams of water objects. Water management in Russia: problems, technologies, management (Russian Research Institute of Integrated Use and Protection of Water Resources, Ekaterinburg, 2009)

4. L.A. Bespalova, S.V. Berdnikov, Workshop on hydrology staging and conducting observations on the Rivers: educational-methodical manual (Southern Federal University, Rostov-on-Don, 2016)

5. V.S. Borovkov, Channel processes and dynamics of River flows in urban areas (Gidrometeoizdat, Leningrad, 1989)

6. V.A. Shlychkov, Numerical modeling of River flows with allowance for vortex generation at the bed-floodplain boundary, Water resources. - U. 35, 546-553 (2008).

7. V.V. Kramarenko, Ground science: a textbook,( Yurayt Publishing House, Moscow, 2016) 